\title{
The Rate and Structure of Causes in Development of Secondary Metabolic Nephropathy in Children
}

IJCRR

Section: Healthcare

Sci. Journal Impact

Factor: $6.1(2018)$

ICV: $90.90(2018)$

Scopus'

\section{Sharipov Alisher Mirkhamidovich, Artikova Magina Akmalovna, Akhmatalieva Mayram Akhmatalievna}

Department of Emergency Pediatrics, Disaster Medicine, Tashkent Pediatric Medical lnstitute, Tashkent, Uzbekistan..

\section{ABSTRACT}

Metabolic disorders nephropathy (MDN) is a large group of kidney diseases with various etiologies and pathogenesis, but combined in that their development is associated with metabolic disorders that can lead to changes in the functional state of the kidneys or structural changes at the level of various structures of the nephron. Statistical variation in the registration of MDN ranges from $27 \%$ to $64 \%$ in the structure of the incidence of the urinary system in children, and in everyday practice of a pediatrician, almost every third patient has a syndrome of metabolic disorders in the urine. Establishing the nature of crystalluria as the cause of metabolic nephropathy, at what age the manifestations of MDN most often debut, the gender characteristics of this pathology, and finally, the determination of the genealogical relationship is a widely discussed focus of research on this field. Therefore, our results showed that oxalate-calcium crystalluria accounted for the majority of cases of crystalluria, especially from 6 months to 7 years of age, which predetermined the majority of cases of secondary oxalate nephropathy, especially in boys who had a longer course of oxaluria. Genealogical analysis of anamnestic data reflected the high incidence of kidney stones diseases and dysuric syndrome, which correlated with a hereditary burden in the gastrointestinal tract, among parents and immediate relatives of the studied children with SMN.

Key Words: Metabolic disorders nephropathy, Secondary oxalate nephropathy, Crystalluria, Oxalate-calcium crystalluria.

\section{INTRODUCTION}

Despite significant progress in the development of pediatric nephrology, over the past decade, the problem of kidney disease remains relevant. Among the pathologies of the urinary system, there is an increase in metabolic diseases, such as metabolic nephropathy ${ }^{3}$. In the structure of the incidence of the urinary system in children, it accounts for from 27 to $64 \%{ }^{5}$. In the vast majority of cases, secondary oxalate nephropathy is detected. Its share among metabolic nephropathies is significant and ranges from 68 to $71 \%{ }^{4}$. The frequency of calcium oxalate crystalluria is 160 per 1000 cases, and secondary oxalate nephropathy is 32 per 1000 children ${ }^{9}$.

\section{The Aim of the Study}

To determine the frequency and structure of development of secondary oxalate nephropathy.

\section{MATERIALS AND METHODS}

In order to establish the frequency and structure of the development of secondary metabolic nephropathy (SMN) during the analyzed period from 2017 to 2019 . A retrospective analysis of 1020 outpatient cards was carried out in Central Diagnostic Clinic No. 1 in Tashkent. According to our analysis, we sampled clinical material with signs of various crystalluria variants, which were generally established in 281 children aged 6 months and older under 18 years old.

\section{RESULTS AND DISCUSSION}

To identify the occurrence of various crystalluria variants in the clinical material of our study, we used methods for determining urinary sediment crystals. Our results reflected that in 281 children (chart 1), oxalate-calcium crystalluria was most often determined in $68.7 \%$ of cases. The frequency of

\section{Corresponding Author:}

Sharipov Alisher Mirkhamidovich, Department of Emergency Pediatrics, Disaster Medicine, Tashkent Pediatric Medical Institute, Tashkent, Uzbekistan.

ISSN: $2231-2196$ (Print)

ISSN: 0975-5241 (Online)

Received: 23.04 .2020

Revised: 09.06 .2020

Accepted: 21.06 .2020

Published: 22.07 .2020 
uraturia in our study was $19.6 \%$ of cases, phosphaturia was observed much less frequently - in $7.3 \%$ of cases, and even less often - tripelfosphaturia in $4.3 \%$ of cases. Therefore, in the structure of the causes of the development of secondary oxalate nephropathy by frequency, we determined oxalatecalcium crystalluria, which corresponds to most opinions in the world literature. However, according to the literature, the results of research reports regarding the incidence of secondary oxalate nephropathy in different age groups of children and adolescents reflect disagreements on this issue. Therefore, we used the age groups recommended by WHO and studied the frequency and structure of crystalluria.

This analysis showed that in 281 cases (see Figure 2), manifest crystalluria was most often determined by oxalate-calcium crystalluria at the age of 6 months. up to 7 years old (in $62 \%$ ) and only in $9 \%$ of cases did oxalate-calcium crystalluria manifest at the age of 7 to 11 years. While uraturia was most often observed in children aged 7 to 18 years (in 65\%), and did not occur in infants. Phosphaturia was most detected in children aged 6 months to 3 years $(62 \%)$, tripelfosphaturia was found almost identically in all age groups. Consequently, the most frequent manifest variant of crystalluria was oxalate-calcium crystalluria (in $69 \%$ of cases), which most often developed in children from the age of 6 months. up to 7 years $(62 \%)$. Further, in the frequency of crystalluria, we noted uraturia (in $20 \%$ of cases), which was more determined in children over the age of 7 years (in 65\%). Phosphaturia and tripelfosphaturia were established by us in rare cases (in $7 \%$ and $4 \%$, respectively).

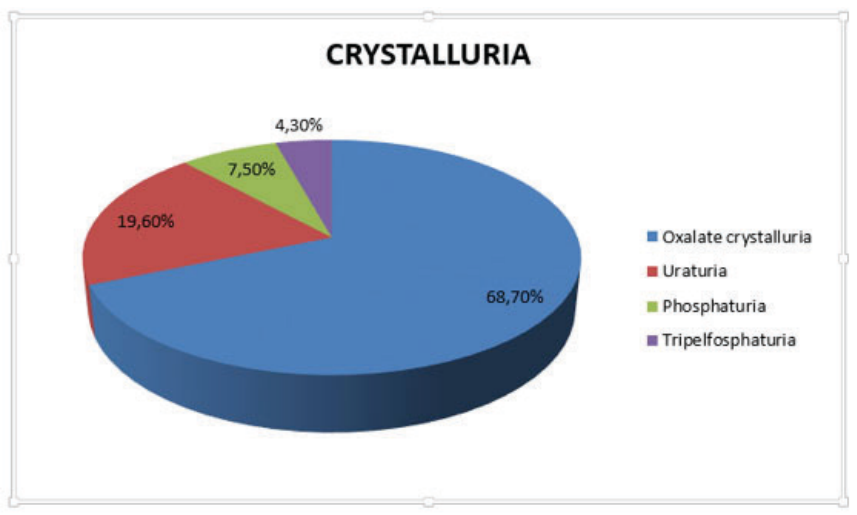

Figure 1: The structure of crystalluria in 281 children.

Thus, a retrospective analysis of 281 outpatient maps showed that OCDs constitute the majority of cases of crystalluria, especially at the age of 6 months to 7 years. Therefore, the main group of our study included 76 children with secondary oxalate nephropathy (secondary oxalate nephropathy) under the age of 7 years, compliance with the standard study complex, including indicators of calcium oxalate crystalluria, micro and / or macrohematuria, proteinuria and abacterial leukocyturia. To provide evidence and determine the statisti- cal reliability of the results of a scientific study, the study included a control group of 30 children of the same age category with calcium oxalate crystalluria (OCC) without signs of secondary oxalate nephropathy development.

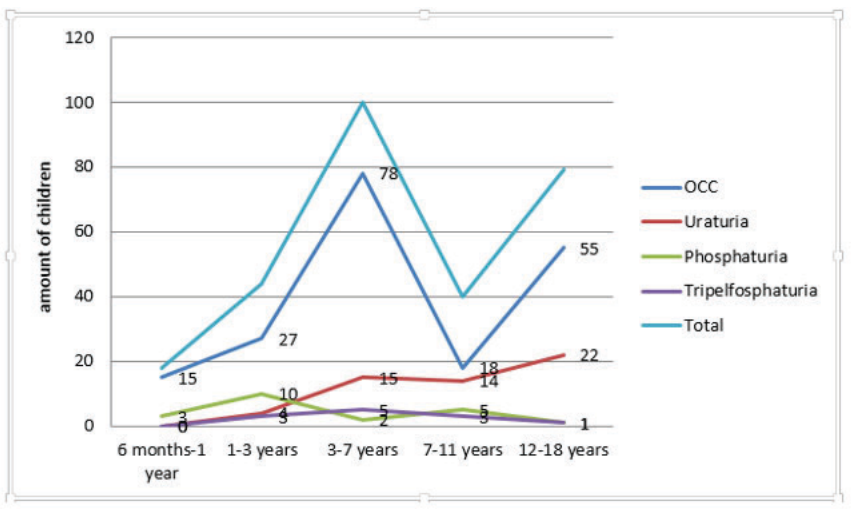

Figure 2: Characteristics of the age composition of children with crystalluria.

The results of our study regarding the age structure of the studied children of the main group showed (Table 1) that the least diagnosed was secondary oxalate nephropathy in children under the age of 1 year $(6.6 \%, \mathrm{n}=5)$, and more often in young children $(38.2 \%, \mathrm{n}=18)$, and at preschool age (from 3 to 7 years) secondary oxalate nephropathy was diagnosed most often - in $69.7 \%$ of cases. In the control group of the studied children with oxalate-calcium crystalluria, the same picture was observed, namely, infants and young children were less likely (20 and $10 \%$, respectively). More often in the control group (in $70 \%$ of cases, $n=21$ ) children prevailed whose age was determined by the preschool period (3-7 years). Therefore, a comparative analysis of the age structure in the main and control groups did not establish significant differences.

The study of gender characteristics showed that in the main group secondary oxalate nephropathy developed to a greater extent in girls (57\%) than boys (43\%), in contrast to the control group, where there were significantly more boys $(60 \%$ and $40 \%$, respectively). In the age categories of the main group, we did not establish any significant differences by gender, i.e. regardless of age, the number of girls in the main group prevailed over the number of boys. Whereas in the control group only in the age group of 3-7 years, the number of boys prevailed over the number of girls by more than 1.5 times, which reflected a more frequent development of secondary oxalate nephropathy in girls, despite the predominance of boys with signs of oxalate crystalluria.

Analysis of the first manifestation of oxaluria in the compared groups showed that in the main group, oxalates were first detected more often in children in the age category up 
to 3 years (in $68.4 \%$ of cases), and in $18.4 \%$ of cases, the debut of crystalluria was noted in the age category of 3 up to 7 years. In the control group, for the first time, oxalates were established more often at the age of 3 to 7 years (in $63.3 \%$ of cases) and $26.7 \%$ of cases at the age of 3 years. In infancy, in both compared groups of our study, the debut of oxaluria was significantly less common (13 and $10 \%$, respectively). In the study group, the duration of the course of oxalate crystalluria was about 2.5 years $(\mathrm{M}+\mathrm{m}=28.21+2.44$ months $)$, and in the control group a little less than 1 year $(\mathrm{M}+\mathrm{m}=11.43$ $+3,27$ ), which reflects a longer manifestation of oxaluria in children who have developed signs of secondary oxalate nephropathy.

Table 1: Age and gender characteristics of children of the main (secondary oxalate nephropathy) and control (oxalate-calcium crystalluria) groups.

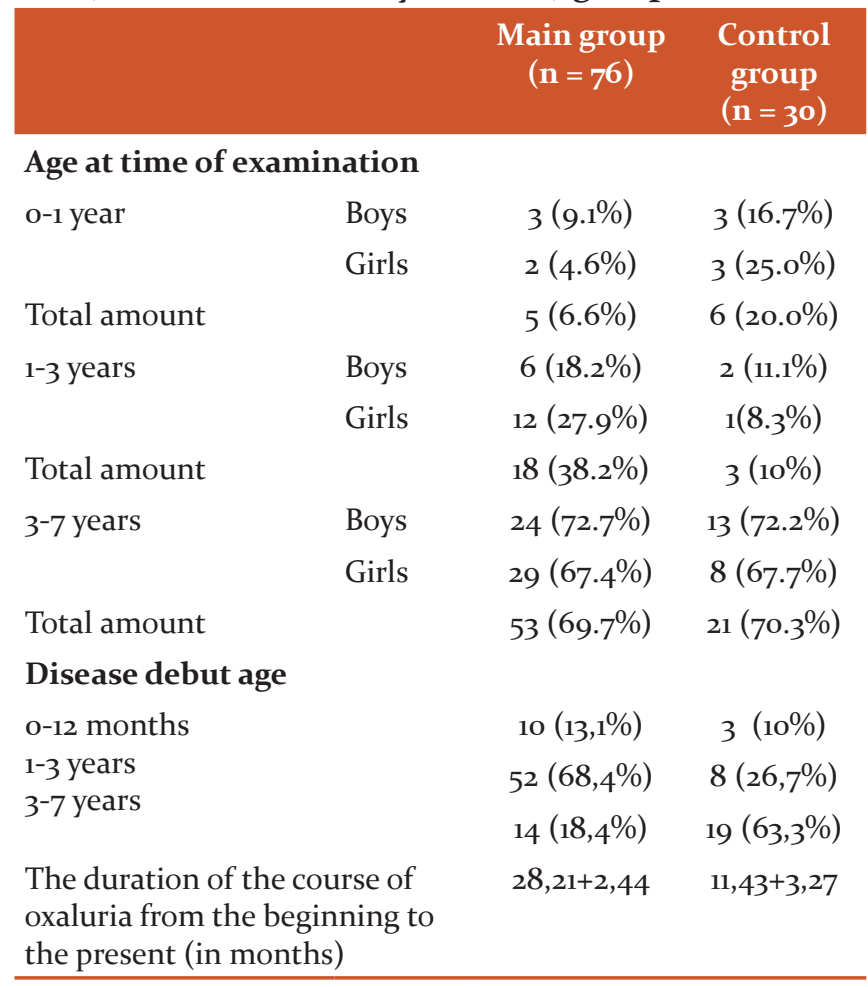

Consequently, in children with secondary oxalate nephropathy signs, the debut of oxaluria was established significantly earlier than in the control group, therefore, our results reflect a longer course of oxaluria in the main group compared with the group of children without secondary oxalate nephropathy signs.

Taking into account the established opinion of researchers and recommendations in the scientific literature on the influence on relatives of family members of this pathology of the diseases of the urinary system diseases ${ }^{1,2,8,6}$, as well as on the high incidence of secondary oxalate nephropathy, urinary tract infection, tubulointerstitial nephritis, and urolithiasis disease in children with maternal pyelonephritis ${ }^{7}$, the genealogical history and associated pathological conditions were comprehensively studied in our work (see table 2).

The study of the genealogical history in the main group showed that the closest relatives of the studied children most often revealed pathology of the urinary system - in $85.5 \%$ of cases. At the same time, parents and other relatives pointed to their diagnosis of urolithiasis in every third case (32.9\%), complaints in the form of dysuria in $17 \%$ of cases, and hematuria in $13 \%$. The remaining close relatives noted in history that in $11.8 \%$ of cases metabolic nephropathy was detected, in $6.6 \%$ - nephritis and $2.6 \%$ - congenital anomalies of the kidneys. In the control group, only in $20 \%$ of the cases, the history of the closest relatives revealed pathology of the urinary system, including urolithiasis disease and dysuria in $13.5 \%$ of cases, and in other cases, signs of metabolic nephropathy and hematuria were found equally. We did not observe nephritis and congenital anomalies of genitourinary systemin relatives of the control group.

In the structure of aggravated heredity in children of the main group, it was noted that in $43 \%$ of cases relatives had gastrointestinal diseases, which were largely presented in the form of chronic gastroduodenitis (10.5\%) and cholecystitis $(10.5 \%)$, and to a lesser extent degree - gallstone disease $(6.6 \%)$ and irritable bowel syndrome (6.6\%). To a sufficient extent, we established a burdened history of metabolic disorders, which were found in the main group in $27.6 \%$ of cases. These pathological conditions were presented in the form of metabolic syndrome (in $10.5 \%$ of cases), gout (in $6.6 \%$ ), and obesity (in $10.5 \%$ ). A study of the structure of gastrointestinal diseases in families of children of the control group showed the lowest degree of the hereditary burden for gastrointestinal diseases (in $13.3 \%$ of cases). At the same time, in the control group, we noted the average degree of burdened history of metabolic disorders, which occurred in $26.6 \%$ of cases.

\section{CONCLUSIONS}

The results of our study showed that oxalate-calcium crystalluria makes up the majority of cases of crystalluria, especially from 6 months to 7 years of age, which determines the majority of cases of secondary oxalate nephropathy, especially in boys. At the same time, the debut of oxaluria was established reliably earlier, which became the main reason for the longer course of oxaluria in the main group compared with the group of children without signs of secondary oxalate nephropathy. Genealogical analysis of anamnestic data showed that parents and immediate relatives of the studied children with secondary oxalate nephropathy were identified with a high frequency of urolithiasis disease and dysuric syndrome, which correlated with hereditary burden of gastrointestinal diseases. 
Acknowledgement: Authors acknowledge the immense help received from the scholars whose articles are cited and included in references of this manuscript. The authors are also grateful to authors / editors / publishers of all those articles, journals and books from where the literature for this article has been reviewed and discussed.

Conflict of interest: None

Financial support: None

\section{REFERENCES}

1 Veltishchev Yu.E., Yuryeva EA, Derzhavin V.M., Dyatlova N.M. Multi-organ membrane pathology in children (Collection of scientific articles) .- M., 1991. -P.201

2. Birkou R., Fletcher E. Guide to medicine. Diagnosis and therapy. Volume 2 .. Per. with English - M .: Mir, 1997. - P. $152-153$

3. V.V. Dlin, I.M. Osmanov, Length V.V. Dysmetabolic nephropathy with calcium oxalate crystalluria, Effective pharmacotherapy. - 2013. - No. 42. - P. 8-16.
4. Dlin V.V., Ignatova M.S., Osmanov I.M. Dysmetabolic nephropathy in children. Russian Bulletin of Perinatology and Pediatrics 2013.T58.№5.P.36-45.

5. Zhigunova A.K. Complex therapy for dysmetabolic nephropathy of various origins. The role of herbal medicine, Family medicine 2013.№4 (96) .VII / VIII. P. $37-44$

6. A. V. Malkoch, V. A. Gavrilova, Dysmetabolic nephropathies in children attending physician. 2006. No. 1. - P. 32-36.

7. Curhan GC, Willett WC, Rimm EB, Rimm EB, Stampfer MJ. A prospective study of dietary calcium and other nutrients and the risk of symptomatic kidney stones. N Engl J Med. 1993. Vol. 328, N12. P. 833838.

8. Smith L.H. Diet and hyperoxaluria in the syndrome of idiopathic calcium oxalate urolithiasis. American J. of Kidney Diseases. - 1991. - Vol. 17. - N.4. -P. 370-375

9. Tekgul S., Riedmiller H., Dogan H.S., Hoebeke P., Kocvara L. et al. Guidelines on Paediatric Urology. European Society for Paediatric Urology. 2013. 